\title{
Parametric analysis of rail vehicle parameters influencing ride behavior
}

\author{
R.C. Sharma ${ }^{1 *}$ \\ ${ }^{1 *}$ Department of Mechanical Engineering Maharishi Markandeshwar University, Mullana, INDIA \\ "Corresponding Author: e-mail: er_rcs2000@yahoo.co.in, Tel +91-8059930977
}

\begin{abstract}
This paper presents the influence of rail vehicle parameters on vertical and lateral ride behavior. The analysis considers coupled vertical-lateral 37 degrees of freedom mathematical model of an Indian Railway General Sleeper ICF coach formulated using Largangian dynamics. Both vertical and lateral irregularities of the railway track, considered as random function of time are incorporated in analysis. The ride analysis of the mathematical model suggests that discomfort frequency range lies from 4 to $10.5 \mathrm{~Hz}$ and improvements in the design of rail vehicle coach are required for better ride comfort. It is seen from parametric analysis that car body mass, secondary suspension vertical damping, primary suspension vertical damping and wheel base are the most sensitive parameters influencing vertical ride. While lateral ride is significantly influenced by car body mass, roll \& yaw mass moment of inertia and secondary suspension lateral stiffness.
\end{abstract}

Keywords: Parametric analysis; Vertical ride; Lateral ride; Ride comfort, Power spectral density

DOI: http://dx.doi.org/10.4314/ijest.v3i8.5

\section{Introduction}

The dynamics of railway vehicle represents a balance between the forces acting at the wheel-rail contact point, the inertia forces, the forces exerted by the suspension and the gravitational forces. Of these, the basic characteristics at the wheel-rail interface such as friction, geometry, and elasticity in the contact area are hardly under control. But the vehicle configuration, suspension and to some extent track parameters can be varied over a certain range, limited by different criteria of performance i.e. lateral stability, ride comfort, curve negotiation, wear, dynamic loads and economy considerations.

The travel of rail vehicle on track is always a coupled motion. There exists a coupling between vertical and lateral motions. The vertical irregularities of the track cause both vertical and lateral vibrations in the rail vehicle. In addition, the different rigid bodies i.e. carbody, bolsters, bogie frames and wheel axles execute different angular motions i.e. roll, pitch and yaw which influence the dynamics of the rail vehicle system significantly. In developing the mathematical model to study vertical response, it would not be adequate to include bounce, pitch and roll degrees of freedom of the components. On the other hand, for the lateral response model, it would not be sufficient to use lateral, yaw and roll degrees of freedom of the components. There has been extensive work done by researchers on lateral and vertical dynamics of the rail vehicle to analyse these motions separately. The coupled dynamics of railway vehicle has also been studied (Zhai et al., 1996 and 2009) in the past. Largrangian method is generally used for the analysis of coupled vertical-lateral dynamics of moving vehicle. This method has been used earlier for the analysis of verticallateral dynamics of four wheel roadway vehicle (Nathoo and Healey, 1978) and of three-wheel roadway vehicle (Ramji, 2005).

In the present work a coupled vertical-lateral mathematical model of an Indian Railway General Sleeper Coach is formulated using Largangian dynamics and its vertical and lateral motion has been studied. Both vertical and lateral irregularities of railway track are incorporated and are considered as random function of time. The mathematical model is validated comparing simulated results with vertical and lateral acceleration data obtained through actual rail vehicle testing and the ride comfort is evaluated using specified international standards (ISO 2631, 1997).

The objective of present work is the parametric study of railway vehicle in the context of vertical and lateral ride behavior. The ride behavior of the rail vehicle is studied by varying its one parameter at a time in order to estimate its individual effect on vertical and lateral ride. The rail vehicle parameters taken into consideration are carbody mass and roll, pitch, yaw mass moment of inertia 
values, primary \& secondary suspension parameters and wheelbase of bogie frame. The present study is carried out in the frequency region of interest of human vibration sensitivity. The effect of each parameter on ride behavior is studied by varying original value from $-20 \%$ to $+20 \%$.

\section{Mathematical modelling}

\section{2(a). Vehicle Model}

The railway vehicle as shown in Figure 1(a) and Figure 1(b) comprises of a carbody supported by two bogies one at each end. Bolsters are the intermediate member between the carbody and each bogie frame and is connected to carbody through side bearings. The bogie frame supports the weight of the carbody through a secondary suspension located between the carbody and the bogie frame. In passenger vehicles, each bogie usually consists of two wheel axles that are connected through the primary suspension to the bogie frame. In addition, the wheels are usually tapered or profiled to provide a self centering action as the axle traverses the track. In the present analysis both vertical and lateral irregularities of railway track, considered as random function of time are incorporated. The vehicle model is formulated assigning 37 degrees of freedom to its main rigid bodies (Table 1) with following assumptions.

- The rail vehicle is symmetric along longitudinal plane.

- The rail vehicle is travelling at constant speed such that in the longitudinal degree of freedom is not a rigid body motion.

- All springs and dampers are assumed to be linear.

- Creep forces are assumed as linear and are determined using linear Kalkar's theory (Kalkar, 1979).

- Car body is assumed to be rigid.

- The wheel and rail do not loose contact during motion.

Table 1. Rigid bodies and their degree of freedoms

\begin{tabular}{|c|c|c|c|c|c|}
\hline \multirow[t]{2}{*}{ Components (rigid bodies) } & \multicolumn{5}{|l|}{ Motion } \\
\hline & Lateral & Vertical & Roll & Pitch & Yaw \\
\hline Carbody & $y_{1}$ & $z_{1}$ & $\theta_{1}$ & $\phi_{1}$ & $\psi_{1}$ \\
\hline Front Bolster & $y_{2}$ & $z_{2}$ & $\theta_{2}$ & & \\
\hline Rear Bolster & $y_{3}$ & $z_{3}$ & $\theta_{3}$ & & \\
\hline Front Bogie Frame & $y_{4}$ & $z_{4}$ & $\theta_{4}$ & $\phi_{4}$ & $\psi_{4}$ \\
\hline Rear Bogie Frame & $y_{5}$ & $z_{5}$ & $\theta_{5}$ & $\phi_{5}$ & $\psi_{5}$ \\
\hline Front Bogie Front Wheel-Axle Set & $y_{6}$ & $z_{6}$ & $\theta_{6}$ & & $\psi_{6}$ \\
\hline Front Bogie Rear Wheel-Axle Set & $y_{7}$ & $z_{7}$ & $\theta_{7}$ & & $\psi_{7}$ \\
\hline Rear Bogie Front Wheel-Axle Set & $y_{8}$ & $Z_{8}$ & $\theta_{8}$ & & $\psi_{8}$ \\
\hline Rear Bogie Rear Wheel-Axle Set & $y_{9}$ & $z_{9}$ & $\theta_{9}$ & & $\psi_{9}$ \\
\hline
\end{tabular}

The equations of motion of rail vehicle are obtained in the following form

$[M]\left\{\ddot{y}_{i}\right\}+[C]\left\{\dot{y}_{i}\right\}+[K]\left\{y_{i}\right\}=\left[F_{r}(\omega)\right]$

Where $[M],[K]$ and $[C]$ are the $37 \times 37$ mass, stiffness and damping matrices respectively for vehicle. 


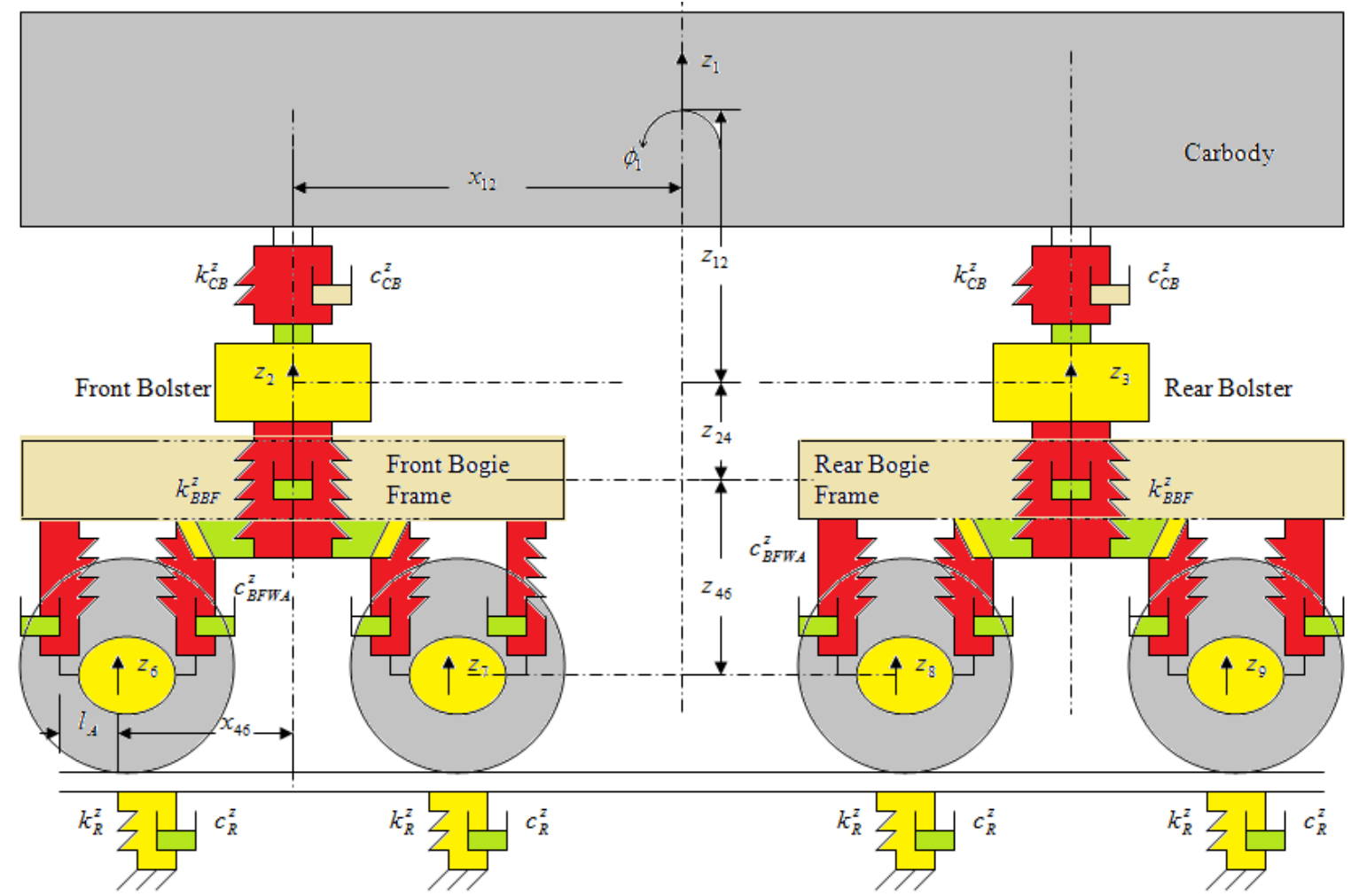

Figure 1(a). Rail -Vehicle model (front view)
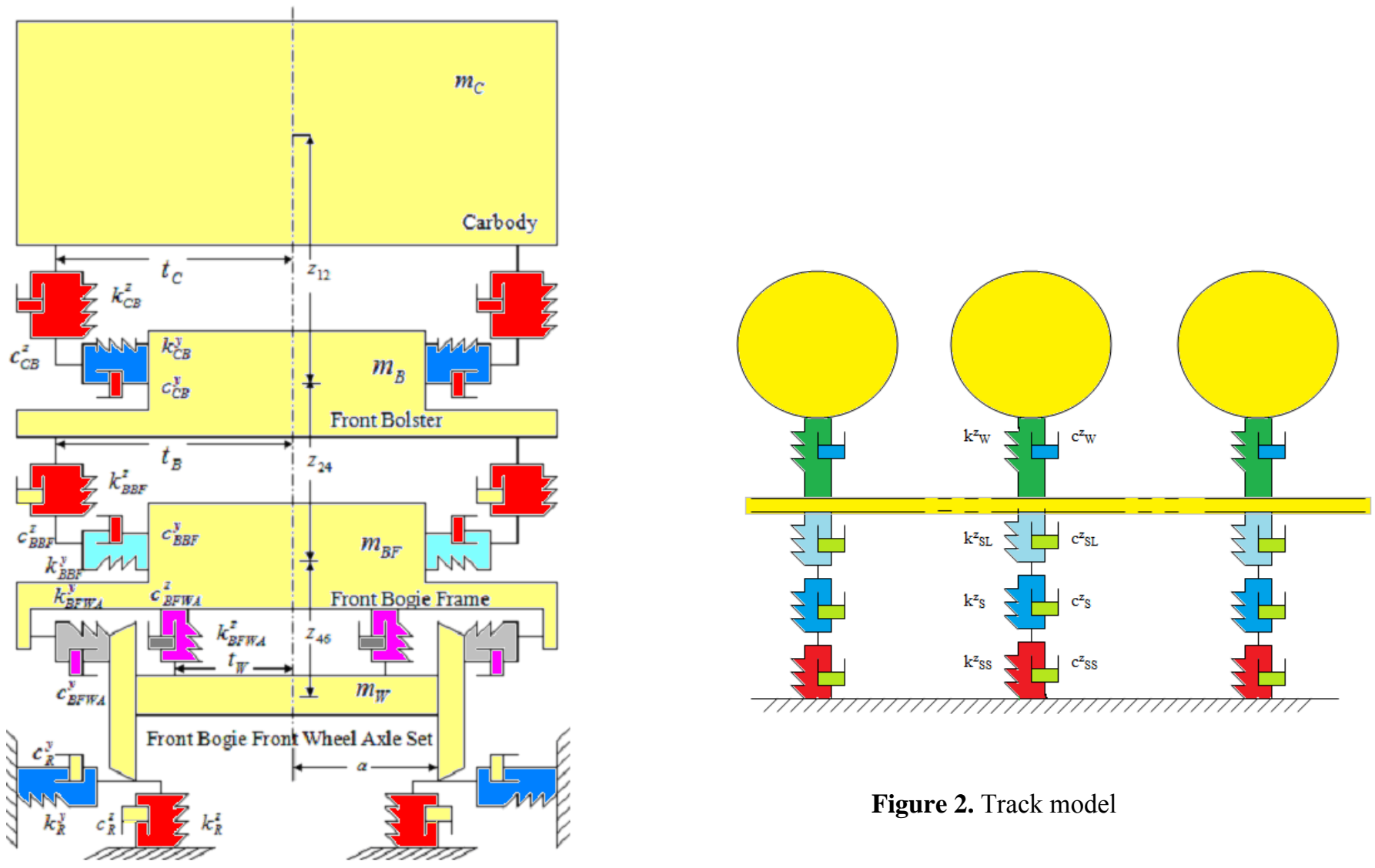

Figure 1(b). Rail-Vehicle model (end view) 


\section{2(b). Track model}

The track may be divided into a superstructure and a substructure. The superstructure includes rails, rail fastenings, pads, sleepers and ballast (i.e. soil). The sub grade or subsoil is the substructure of a track. The track in the present analysis is assumed to be flexible in both vertical and lateral directions. Its flexibility is accounted by considering wheel to be in series with sleeper, soil and subsoil (Figure 2).

$1 / k_{R}^{z}=1 / k_{W}^{z}+1 / k_{S L}^{z}+1 / k_{S}^{z}+1 / k_{S S}^{z}$
$1 / c_{R}^{z}=1 / c_{W}^{z}+1 / c_{S L}^{z}+1 / c_{S}^{z}+1 / c_{S S}^{z}$

Similarly for lateral direction it can be assumed that

$1 / k_{R}^{y}=1 / k_{W}^{y}+1 / k_{S L}^{y}+1 / k_{S}^{y}+1 / k_{S S}^{y}$

$1 / c_{R}^{y}=1 / c_{W}^{y}+1 / c_{S L}^{y}+1 / c_{S}^{y}+1 / c_{S S}^{y}$

\section{Representation of track roughness}

In present work irregularities in the railway track surface are considered random and represented by power spectral density functions. Vertical and lateral irregularities of a straight track, represented by the Equations (6) to (10) are considered and are of the type $S(\Omega)=C_{s p} \Omega^{-N}$ (Goel et al, 2005). Auto-spectral density variation of vertical unevenness of track surface $\left(\mathrm{mm}^{2} / \mathrm{cycle} / \mathrm{m}\right.$ ) as a function of spatial frequency $\Omega$ at the eight wheel-rail contact points is represented as follows

$$
\begin{aligned}
& s_{11}^{z}(\Omega)=s_{22}^{z}(\Omega)=\ldots=s_{88}^{z}(\Omega)=0.0958 \Omega^{-2.1382} \\
& \text { Where } s_{11}^{z}(\Omega), s_{22}^{z}(\Omega), \ldots, s_{88}^{z}(\Omega) \text { are the diagonal elements of the matrix } S_{r}(\Omega)_{8 \times 8}
\end{aligned}
$$

It is assumed that the vertical input between left and right wheel for a particular axle acts simultaneously and cross-power spectral density function of vertical unevenness between the left and right rail is represented as

$s_{12}^{z}(\Omega)=s_{34}^{z}(\Omega)=s_{56}^{z}(\Omega)=s_{78}^{z}(\Omega)=0.0257 \Omega^{-2.3945}$

The vertical input for different axles act with a time lag which is the ratio of longitudinal distance between them and vehicle speed e.g. the cross spectral density function of vertical unevenness between left wheel of the front bogie front wheel axle and the right wheel of the front bogie rear wheel axle is represented as

$S_{14}^{z}(\Omega)=0.0257 \Omega^{-2.3945} e^{-i \omega T}$

The functions $\mathrm{s}_{14}{ }^{ }$and $\mathrm{s}_{41}{ }^{\mathrm{z}}$ are same except that sign of their imaginary parts are reversed.

Auto-spectral density variation of lateral irregularity of track surface (in $\mathrm{mm}^{2} / \mathrm{cycle} / \mathrm{m}$ ) as a function of spatial frequency $\Omega$ at the eight wheel-rail contact points is represented as follows

$s_{11}^{y}(\Omega)=s_{22}^{y}(\Omega)=\ldots . .=s_{88}^{y}(\Omega)=0.0554 \Omega^{-2.2686}$

It is assumed that the lateral input between left and right wheel for a particular axle acts simultaneously and cross-power spectral density function of lateral irregularity between the left and right rail is represented as

$s_{12}^{y}(\Omega)=s_{34}^{y}(\Omega)=s_{56}^{y}(\Omega)=s_{78}^{y}(\Omega)=0.0287 \Omega^{-2.3082}$

The transformation of spectral density of surface profile expressed in terms of spatial frequency $\left[S_{r}(\Omega)\right]$ so that in terms of temporal frequency $\left[S_{r}(f)\right]$ is that of the speed of the vehicle i.e. $\mathrm{V}($ in $\mathrm{m} / \mathrm{s})$.

$S_{r}(f)=S_{r}(\Omega) / V$ 


\section{Ride behavior}

For computation of complex frequency response function, harmonic input is given at one wheel at a time while the inputs at the remaining wheels are kept zero. Equation 1 may also be written as

$$
\left([M]\left(-\omega^{2}\right)+[C](i \omega)+[K]\right) y_{i} e^{i \omega t}=\left[F_{r}(\omega)\right] q_{r} e^{i \omega t}
$$

The above equation may further be written as

$\left[D_{1}\right] H_{r}(\omega)=F_{r}(\omega)$

$H_{r}(\omega)=\left(y_{i} / q_{r}\right)$ is the complex frequency response function for $r^{\text {th }}$ input. The irregularities in the railway track surface are random and are represented by power spectral density functions. In this work vertical and lateral irregularities are represented by the equation of the type $S(\Omega)=C_{s p} \Omega^{-N}$ (Goel et al., 2005).

For a linear system subjected to random inputs, using input-output relationships for spectral densities, the auto and cross-spectral density matrix of the response $\left[S_{y y}(\omega)\right]$ may be written as

$\left[S_{y y}(\omega)\right]_{37 \times 37}=\left[H_{r}(\omega)\right]_{37 \times 8}\left[S_{r}(\omega)\right]_{8 \times 8}\left[H_{r}(\omega)\right]_{8 \times 37}^{T}$

The complex frequency response functions $\left[H_{r}(\omega)\right]_{37 \times 8}$ can also be defined as the ratio of the response rate to unit harmonic input at a given point. The superscript $\mathrm{T}$ denotes transpose of matrix. It may be noted here that above equation is used independently for vertical and lateral irregularities of the track. In the evaluation of vehicle ride quality, the power spectral density (PSD) for the acceleration of the carbody mass center as a function of frequency is of prime interest. The mean square acceleration response (MSAR) expressed as $\left(\mathrm{m} / \mathrm{sec}^{2}\right)^{2} / \mathrm{Hz}$, which is nothing but PSD of acceleration may be written as

$$
\text { MSAR }=(2 \pi f)^{4}\left[H_{r}(\omega)\right]_{37 \times 8}\left[S_{r}(\omega)\right]_{8 \times 8}\left[H_{r}(\omega)\right]_{8 \times 37}^{T}
$$

Power spectral densities of accelerations of loaded carbody obtained by mathematical modeling in vertical and lateral directions are shown in Figure 3 and Figure 4 respectively. The rail vehicle is considered to be moving at a constant speed of $80 \mathrm{~km} / \mathrm{hr}$ over straight track discussed in Section 3. Since the ride comfort of rail vehicle is evaluated for sitting passengers traveling for short journeys, it will be sufficient for the purpose of ride comfort, to consider ISO fatigue decreased proficiency (FDP) boundary for 4 hours duration only as this is normally the maximum duration of travel time in a seated posture. The result of vertical PSD acceleration response (Figure 3) indicates that the response of loaded GS coach lies well within the ISO-2631 comfort criteria except for frequency range from 5 to $10.5 \mathrm{~Hz}$. The result of lateral PSD acceleration response (Figure 4) indicates that the response of loaded carbody lies well within the ISO comfort criteria except for frequency at nearly $4 \mathrm{~Hz}$, where the peak value is obtained. Therefore it may be concluded on the basis of present analysis that discomfort frequency range lies from 4 to $10.5 \mathrm{~Hz}$ and improvements in the design of rail vehicle are required for better ride comfort.

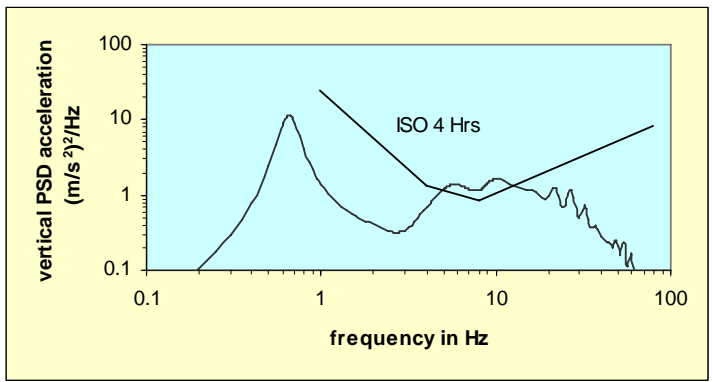

Figure 3. PSD of vertical acceleration $\left(\right.$ in $\left.\left.\left(\mathrm{m} / \mathrm{s}^{2}\right)^{2}\right) / \mathrm{Hz}\right)$ of loaded carbody from simulation

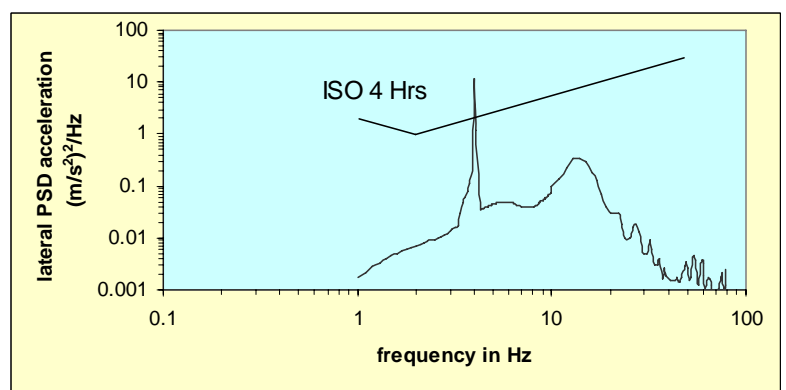

Figure 4. PSD of lateral acceleration $\left(\right.$ in $\left.\left.\left(\mathrm{m} / \mathrm{s}^{2}\right)^{2}\right) / \mathrm{Hz}\right)$ of loaded carbody from simulation

\section{Validation of the mathematical model}

In order to validate the present mathematical model of vehicle and track it is important that simulated results must be compared with results obtained from acceleration measurements through actual testing. The results from actual testing are obtained from Research Designs Standards Organisation, Lucknow. The rail vehicle is moved at a constant speed of $80 \mathrm{~km} / \mathrm{hr}$ over straight track described in Section 3. The data acquisition is completed in two stages. In the first stage the record is obtained for $2 \mathrm{Km}$ straight specimen run-down track and this record is verified covering a long run of about $25 \mathrm{Km}$ in the second stage. A strain gauge 
accelerometer (Range: $\pm 1 \mathrm{~g} \& \pm 2 \mathrm{~g}$; Frequency response: $25 \mathrm{~Hz}$; Excitation: $5 \mathrm{~V}$ AC/DC; Sensitivity: $360 \mathrm{mV} / \mathrm{V} / \mathrm{g}$; Damping: silicon fluid) is placed at floor level near bogie pivot of the rail vehicle. The acceleration data is recorded in time domain with National Instruments cards (Sampling rate: 100 Samples/s, Resolution: 12 Bit) using Lab View software program and this record is converted in frequency domain using Fast Fourier Transformations (FFT). Power spectral densities of accelerations of loaded carbody obtained through actual testing in vertical and lateral directions are shown in Figure 5 and Figure 6 respectively.

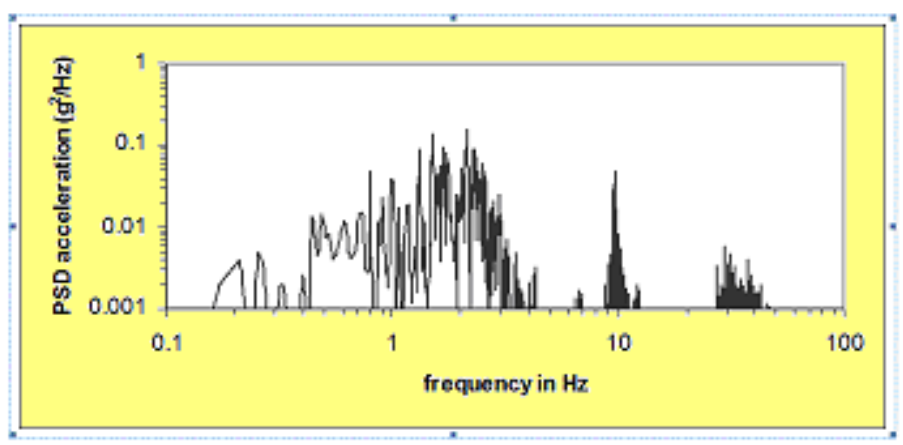

Figure 5: PSD of vertical acceleration (in $\mathrm{g}^{2} / \mathrm{Hz}$ ) of loaded carbody from tests.

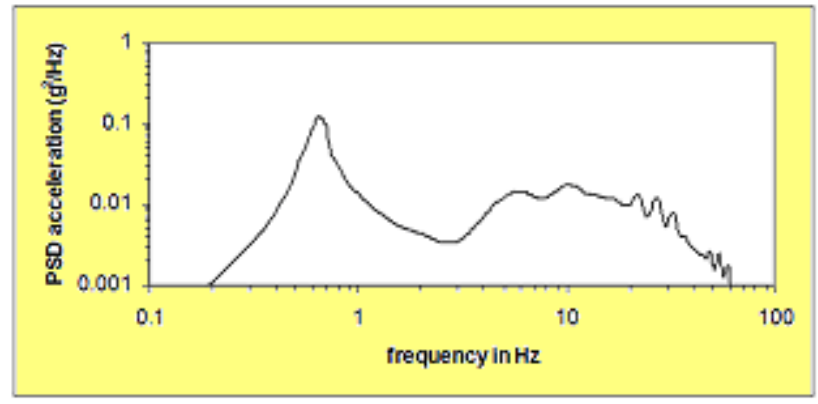

Figure 7: PSD of vertical acceleration (in $\mathrm{g}^{2} / \mathrm{Hz}$ ) of loaded carbody from simulation

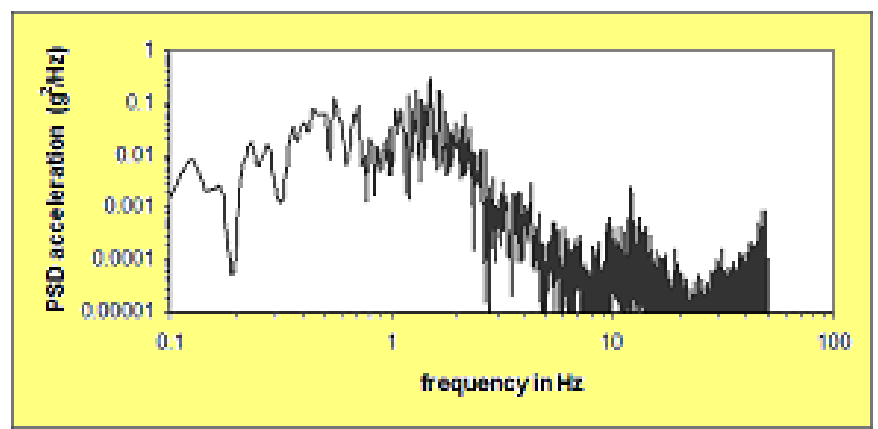

Figure 6: PSD of lateral acceleration (in $\mathrm{g}^{2} / \mathrm{Hz}$ ) of loaded carbody from tests

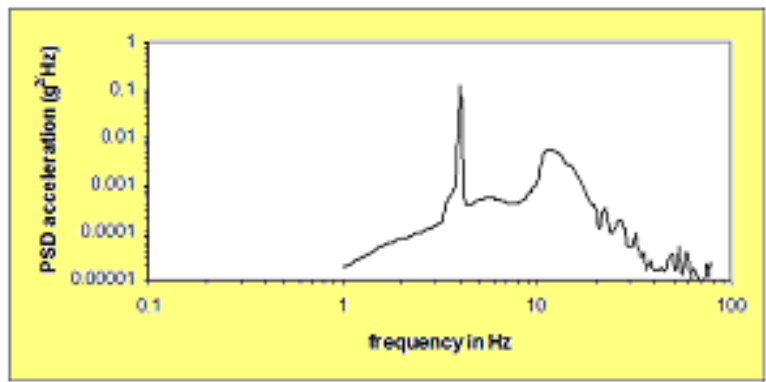

Figure 8: PSD of lateral acceleration (in $\mathrm{g}^{2} / \mathrm{Hz}$ ) of loaded carbody from simulation

Power spectral densities of accelerations (in $\mathrm{g}^{2} / \mathrm{Hz}$ ) of loaded carbody obtained simulations in vertical and lateral directions are shown in Figure 7 and Figure 8 respectively for comparison with actual testing results. The theoretical and actual results compare reasonably well except that the peak values are obtained at slight different frequencies. The limitations of the modelling and tests that are affecting the comparison are as follows:

- The carbody in modeling is assumed as a rigid body discounting the influence of flexible structure.

- Braking system, lower plank and other systems are difficult to be incorporated in the analysis.

- The mass of the track is not considered to any of assigned degree of freedom.

- In actual testing the sensor for acceleration measurements is placed at floor level of bogie pivot. This point is not exactly where the centre of gravity of carbody is concentrated. In simulations the acceleration is determined at centre of gravity of carbody.

- In the present analysis contact patch is assumed as Hertzian ellipse and creep forces are considered as linear function of creepage i.e. wheel axle set displacements and wheel axle set velocities. In actual the creep forces are non-linear functions of wheel-axle set displacements and wheel-axle set velocities.

- In the present analysis suspension forces are assumed as linear function of displacement and velocities within the range of their travel. In actual practice the piecewise linear theory is applicable considering the actual travel of the suspension elements.

- The effect of wind drag forces are not considered in the present analysis. In actual the wind forces from longitudinal and lateral directions significantly affect the dynamics of rail vehicle system.

- It is also possible that there may be a time gap between random inputs measurements of track and acceleration measurements of vehicle as a result of which the track profile may have been changed.

- In the present analysis the random track irregularities are considered as stationary. In actual the sampled track may not be exactly representing the whole track.

- In practice, defects may occur with the passage of time; in the bearings of the wheel axle sets and other moving parts resulting in extra force inputs. 


\section{Parametric analysis and results}

The ride behavior of the loaded carbody has been analyzed in Section 4. To allow optimization of design parameters to improve vehicle ride quality, it will be necessary to conduct parametric analysis as this would provide the rail vehicle designer, vital information regarding the extent to which each parameter influences the PSD or RMS acceleration response of the vehicle, when moving at a constant speed. This information can be utilized to arrive at a suitable combination of the design parameters which can aid in keeping the peak value of accelerations within the ISO comfort boundaries, resulting in an improved ride. Both the PSD and RMS acceleration spectra yield similar information in terms of the magnitude and the frequency range, when used with their respective comfort criteria, PSD acceleration response has been considered for the present study. The vertical PSD acceleration and lateral PSD acceleration values corresponding existing parameters values for an ICF General Sleeper carbody are mentioned in Table 2 at certain frequencies with in the frequency range of human comfort.

Table 2. PSD values of vertical and lateral acceleration corresponding to existing rail vehicle data

\begin{tabular}{|l|l|l|l|l|l|l|l|l|l|}
\hline \multicolumn{2}{|l|}{ Vertical acceleration (PSD) in $\left(\mathbf{m} / \mathbf{s}^{2}\right)^{2} / \mathbf{H z}$} & \multicolumn{4}{c|}{ Lateral accleration (PSD) in $\left(\mathbf{m} / \mathbf{s}^{2}\right)^{2} / \mathbf{H z}$} \\
\hline $0.7 \mathrm{~Hz}$ & $1.0 \mathrm{~Hz}$ & $2 \mathrm{~Hz}$ & $4 \mathrm{~Hz}$ & $10 \mathrm{~Hz}$ & $3 \mathrm{~Hz}$ & $4 \mathrm{~Hz}$ & $7 \mathrm{~Hz}$ & $10 \mathrm{~Hz}$ & $15 \mathrm{~Hz}$ \\
\hline 9.34 & 1.38 & 0.41 & 0.68 & 1.66 & 0.0156 & 11.48 & 0.0507 & 0.0968 & 0.29 \\
\hline
\end{tabular}

The present study is carried out for frequencies from 0.7 to $15 \mathrm{~Hz}$ as the higher frequencies do not affect human vibration sensitivity and lower frequencies are important when motion sickness in passengers is evaluated. The ride behavior of the vehicle is studied by varying one parameter at a time in order to estimate its individual effect. The parameters taken into consideration are carbody mass \& roll, pitch, yaw mass moment of inertia values, spring stiffness \& damping coefficient of primary \& secondary suspensions and wheelbase of the rail vehicle. The effect of each parameter on ride behavior is studied by varying original value from $-20 \%$ to $+20 \%$. Few of the vehicle parameters do not affect either vertical or lateral ride behavior and therefore these parameters are not discussed.

\section{6(a). Influence of carbody parameters on ride behavior}

Carbody parameters varied in the analysis are its mass and roll, pitch \& yaw mass moment of inertia. It has been observed (Figure 9 and Figure 10) that the carbody mass affects both vertical and lateral PSD acceleration responses. Higher value of carbody mass than the existing values is preferred with respect to both vertical and lateral acceleration PSD as the acceleration values are reduced significantly in critical frequency zone i.e. from 5 to $10.5 \mathrm{~Hz}$ for vertical PSD and $4 \mathrm{~Hz}$ for lateral PSD. Higher carbody mass than standard values is also preferred with respect to vertical acceleration PSD values as reduced carbody mass results in shifting the peak acceleration values in lower frequency range towards to ISO comfort boundary. The pitch mass moment of inertia has no effect on lateral PSD acceleration, but it marginally affects vertical PSD values of acceleration. It is observed that reduced pitch mass moment of inertia from existing values is desirable with respect to vertical PSD acceleration in low and high frequency region with slight penalty in mid frequency region. The roll mass moment of inertia has no effect on vertical PSD values of acceleration, but it affects the lateral PSD values of acceleration. The peak values of lateral acceleration at critical frequency i.e. $4 \mathrm{~Hz}$ is slightly reduced with the increase in roll mass moment of inertia. The yaw mass moment of inertia has no effect on vertical PSD values of acceleration, but it significantly affects the lateral PSD values of acceleration.

\section{6(b). Influence of secondary suspension parameters on ride behavior}

Lower secondary suspension vertical stiffness values (Figure 11) from the existing value may be preferred with respect to vertical PSD acceleration as the peak acceleration values in lower frequency zone is significantly reduced. With reduced secondary suspension vertical stiffness peak acceleration is also shifted away from the ISO comfort boundary. But it is also observed that with lower secondary suspension vertical stiffness the vertical acceleration values are slightly increased in critical frequency regions. Lower secondary suspension vertical stiffness values may further be preferred with respect to lateral PSD acceleration as the peak acceleration values is slightly reduced at critical frequency. Higher secondary suspension vertical damping coefficient values from the existing values is preferred with respect to vertical PSD acceleration as the acceleration values is significantly reduced in all frequency regions of our interest. Secondary suspension vertical damping has negligible effect on lateral PSD values of acceleration. Higher secondary suspension lateral stiffness values (Figure 12) from the existing values can be preferred with respect to lateral PSD acceleration as the acceleration values are significantly reduced in all frequency regions of human ride sensitivity. Lower secondary suspension lateral damping coefficient values (Figure 12) from the existing values can be preferred with respect to lateral PSD acceleration as the acceleration values are reduced up to $10 \mathrm{~Hz}$. Secondary suspension lateral stiffness and secondary suspension lateral damping coefficient has negligible effect on vertical PSD values of acceleration.

\section{6(c). Influence of primary suspension parameters on ride behavior}

Lower primary suspension vertical stiffness values (Figure 13) than the existing value is preferred with respect to vertical PSD acceleration as the acceleration values are significantly reduced in lower middle frequency region with slight penalty of increased 
lateral PSD acceleration at critical frequency. The vertical acceleration values in mid frequency region are decreased with lower primary suspension vertical damping coefficient values from the existing value. However with lower primary suspension vertical

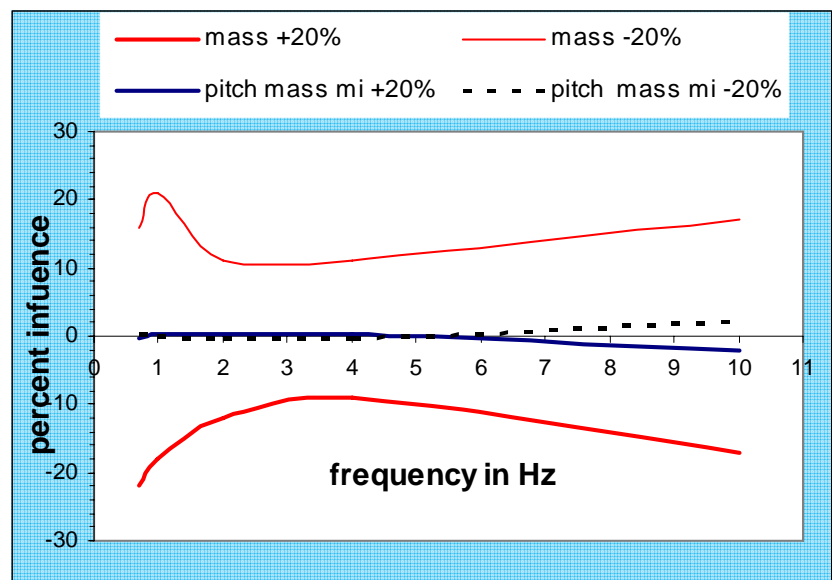

Figure 9. Percent influence of carbody parameters on vertical ride behavior

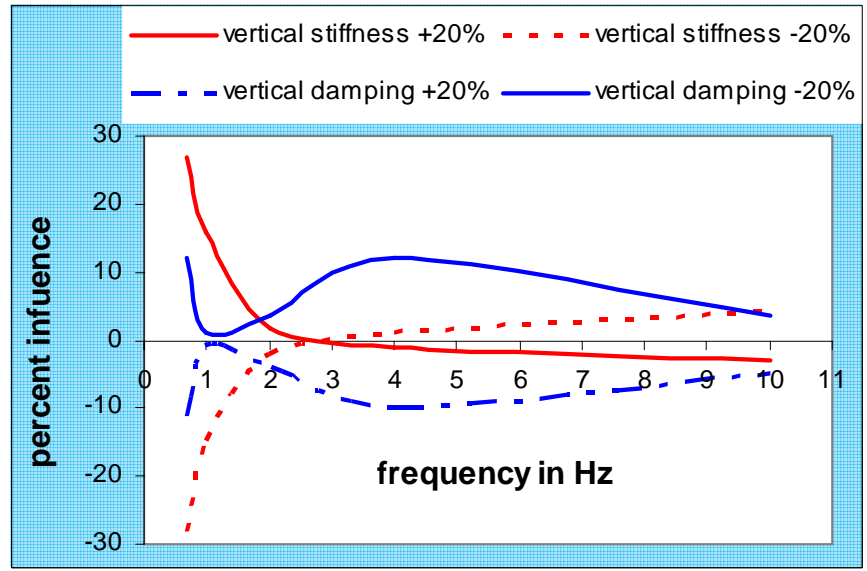

Figure 11. Percent influence of secondary suspension parameters on vertical ride behavior

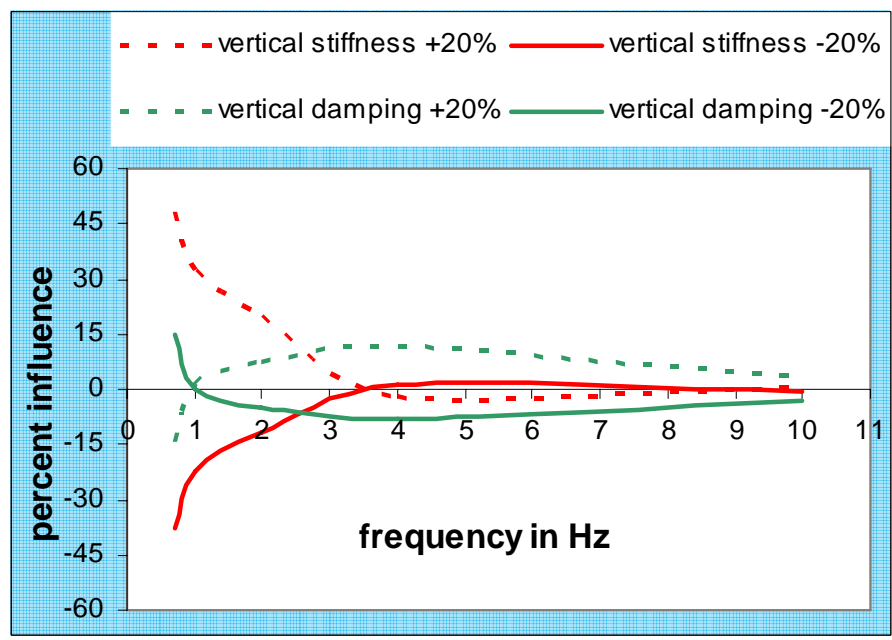

Figure 13. Percent influence of primary suspension parameters on vertical ride behavior

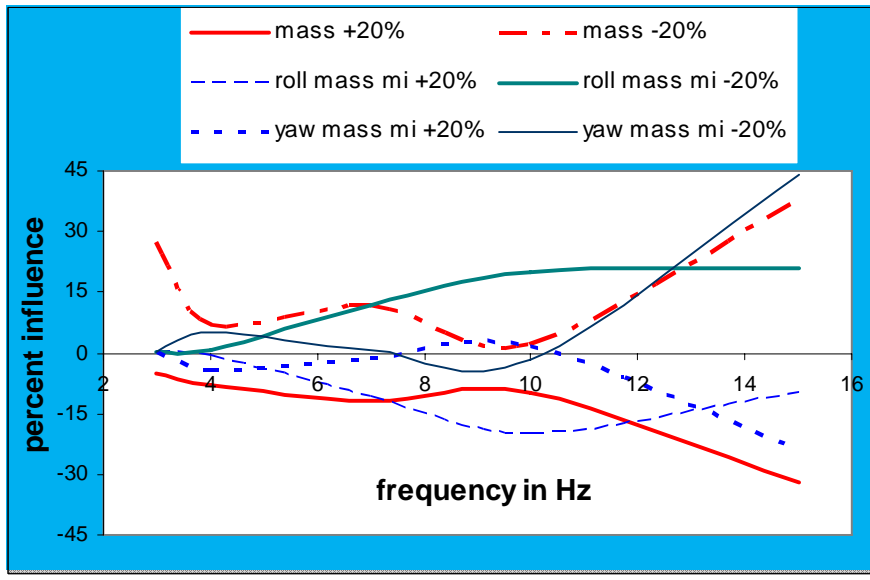

Figure 10. Percent influence of carbody parameters on lateral ride behavior

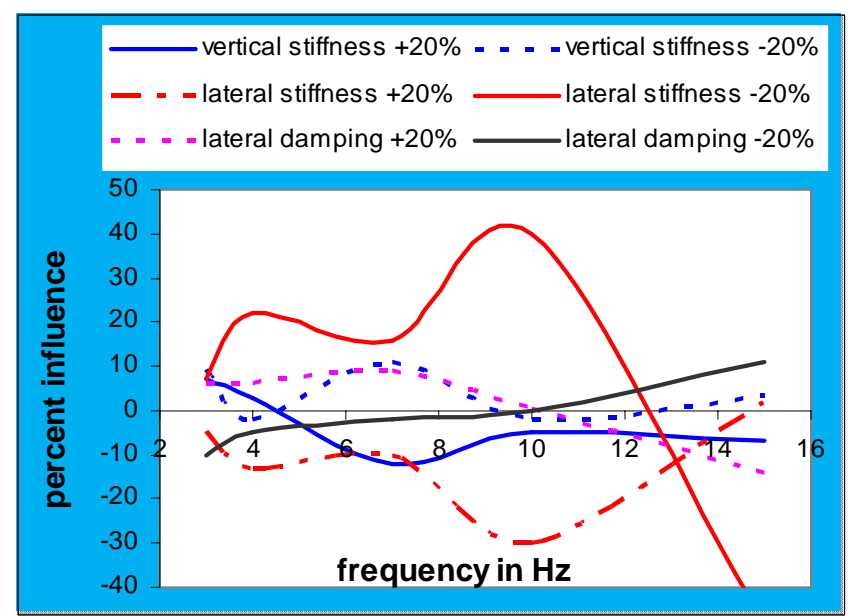

Figure 12. Percent influence of secondary suspension parameters on lateral ride behavior

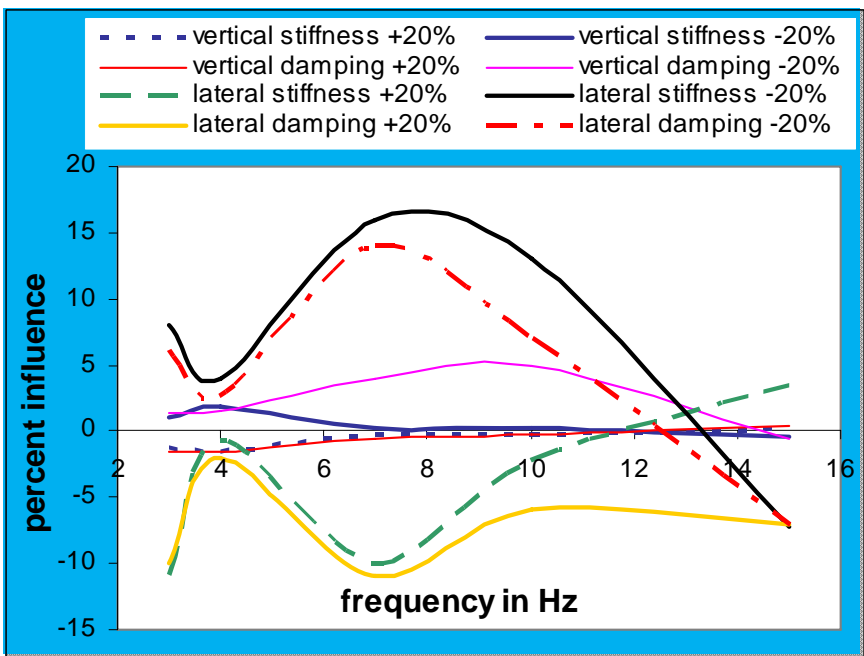

Figure 14. Percent influence of primary suspension parameters on lateral ride behavior 


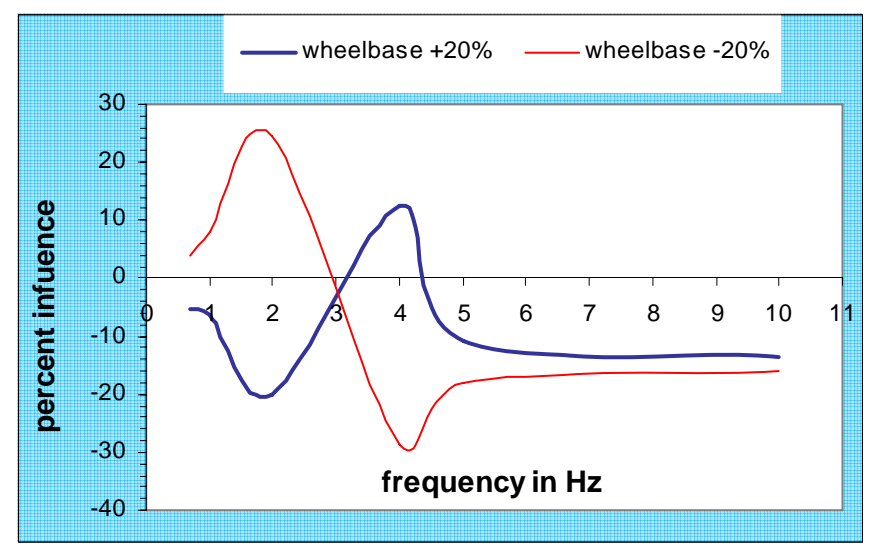

Figure 15. Percent influence of bogie frame wheelbase on vertical ride behavior

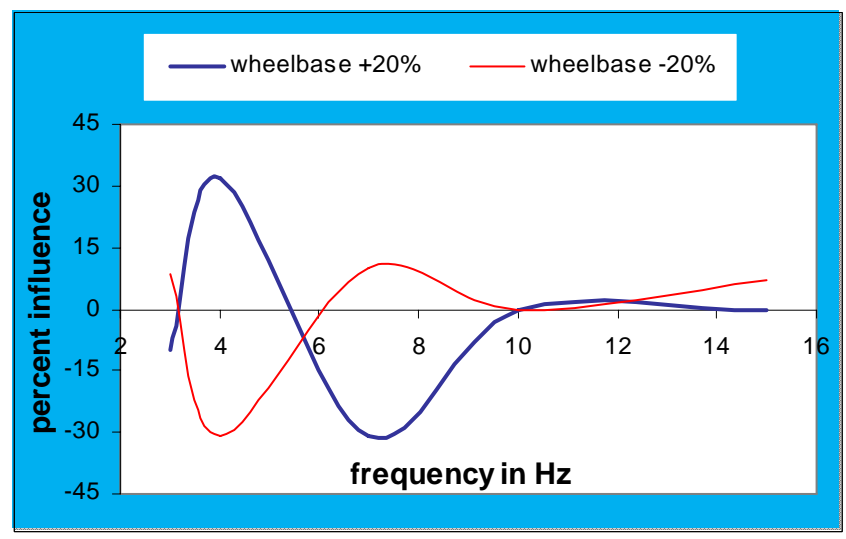

Figure 16. Percent influence of bogie frame wheelbase on lateral ride behavior

damping coefficient values, lateral PSD acceleration is increased in the frequency region of interest. Higher primary suspension lateral stiffness and lateral damping values (Figure 14) from the existing values are preferred with respect to lateral PSD acceleration as the acceleration values are significantly reduced in almost all frequency regions. Primary suspension lateral stiffness and lateral damping has negligible effect on vertical PSD values of acceleration.

\section{6(d). Influence of bogie frame wheelbase on ride behavior}

Higher wheelbase (Figure 15) from the existing value may be preferred with respect to vertical acceleration as the acceleration values are reduced in all frequency regions except from 3 to $4.25 \mathrm{~Hz}$. Lateral PSD acceleration values are increased higher wheelbase (Figure 16) in lower frequency regions and it is also decreased in same way in mid frequency regions. . Lateral PSD acceleration values remains unchanged with wheelbase beyond $10 \mathrm{~Hz}$.

\section{Conclusions}

The conclusions obtained from the ride analysis are as followings:

- The vertical PSD acceleration response of loaded of Indian Railway General Sleeper Coach lies well within the ISO specifications except for frequency range from 5 to $10.5 \mathrm{~Hz}$.

- The lateral PSD acceleration response indicates that the response of loaded GS coach lies well within the ISO specifications except for frequency at nearly $4 \mathrm{~Hz}$, where the peak value is obtained.

The analysis indicates that discomfort frequency range belongs from 4 to $10.5 \mathrm{~Hz}$ and improvements in coach design are required. With the objective of improvement in vertical and lateral ride of the coach parametric study within the frequency range of interest of human ride comfort is analyzed and followings conclusions are obtained:

- Higher carbody mass from existing value improves the vertical \& lateral ride at all frequencies.

- Higher carbody roll mass moment of inertia from existing value improves the lateral ride at all frequencies of human ride sensitivity. Lower carbody yaw mass moment of inertia from existing value improves the lateral ride at frequencies except from 9 to $10 \mathrm{~Hz}$. However this improvement is not appreciable.

- Lower secondary suspension vertical damping from existing value is preferred as it improves the vertical ride after $1 \mathrm{~Hz}$ and is most effective at critical frequencies determined from present ride analysis.

- Higher primary suspension vertical damping from existing value improves the vertical ride uniformly at all frequencies.

- Higher wheelbase from existing value improves the vertical ride at all frequencies except from 3 to $4.25 \mathrm{~Hz}$ and is preferred.

- Lower secondary suspension lateral stiffness from existing value improves the lateral ride at all frequencies.

Few of the vehicle parameters considered in the present analysis marginally influence either vertical or lateral ride and therefore not discussed.

The present ride and parametric study analyzes the single performance indices of the railway vehicle i.e. ride comfort and does not give any information about other performance indices i.e. lateral stability, curve negotiation ability, wear. The change in the existing value of a particular parameter studied in this work may improve its ride comfort but this may deteriorate lateral stability. Increment in mass of carbody and mass moment of inertia (roll, pitch \& yaw) improve the vertical and lateral ride as investigated in this analysis but may increase the permissible wear in the track. However present work is helpful to the rail vehicle designer in the way that if another parametric study is carried out in order to analyze another performance indices i.e. lateral stability on a straight track and it is investigated from that study change in existing value of a particular suspension parameter improves lateral 
stability, the change in existing value of same parameter improves either vertical or lateral ride comfort which is investigated from this analysis (moreover railway vehicle is not running on curves for a particular railway line), a sufficient thought can be given regarding the change.

\section{Nomenclature}

$m_{C, B} \quad$ Mass of carbody and bolster respectively

$m_{B F, W}$ Mass of bogie frame and wheel axle respectively

$I_{C}^{x, y, z} \quad$ Roll, pitch and yaw mass moment of inertia of carbody respectively

$I_{B}^{x, y, z} \quad$ Roll, pitch and yaw mass moment of inertia of bolster respectively

$I_{B F}^{x, y, z} \quad$ Roll, pitch and yaw mass moment of inertia of bogie frame respectively

$I_{W}^{x, y, z} \quad$ Roll, pitch and yaw mass moment of inertia of wheel axle respectively

$k_{C B}^{z, y} \quad$ Vertical (1/2 part) and lateral (1/2 part) stiffness between carbody and bolster respectively

$c_{C B}^{z, y} \quad$ Vertical (1/2 part) and lateral (1/2 part) damping coefficient between carbody and bolster respective

$k_{B B F}^{z, y} \quad$ Vertical (1/4 part) and lateral (1/2 part) stiffness between bolster and bogie frame respectively

$C_{B B F}^{z, y} \quad$ Vertical and lateral damping coefficient between bolster and bogie frame respectively ( $1 / 2$ part)

$k_{B F W A}^{z, y} \quad$ Vertical ( $1 / 4$ part) and lateral (1/2 part) stiffness between bogie frame and corresponding wheel axle

$c_{B F W A}^{z, y} \quad$ Vertical (1/4 part) and Lateral (1/2 part) damping coefficient between bogie frame and corresponding wheel axle

$k_{W}^{z, y} \quad$ Vertical and lateral Hertzian stiffness of wheel respectively

$k_{S L}^{z, y} \quad$ Vertical and lateral stiffness of sleeper respectively

$k_{S}^{z, y} \quad$ Per unit area vertical and lateral stiffness of soil respectively

$k_{S S}^{z, y} \quad$ Per unit area vertical and lateral stiffness stiffness of subsoil respectively

$k_{R}^{z, y} \quad$ Vertical and lateral stiffness of track respectively

$C_{R}^{z, y} \quad$ Vertical \& lateral damping coefficient of track respectively

$t_{W} \quad$ Lateral distance from bogie frame centre of gravity to corresponding vertical suspension between bogie frame and wheel axle

$t_{C} \quad$ Lateral distance from carbody centre of gravity to side bearings

$t_{B} \quad$ Lateral distance from bolster centre of gravity to vertical suspension between bolster and bogie frame

$l_{A} \quad$ Longitudinal distance from wheel axle set centre of gravity to vertical suspension between corresponding bogie frame and wheel axle

$Z_{12} \quad$ Vertical distance between carbody centre of gravity and bolster centre of gravity

$Z_{24} \quad$ Vertical distance between bolster centre of gravity and bogie frame centre of gravity

$Z_{46} \quad$ Vertical distance between bogie frame centre of gravity and corresponding wheel axle centre of gravity

$X_{12} \quad$ Longitudinal distance between carbody centre of gravity and bolster

$X_{46} \quad$ Longitudinal distance between bogie frame centre of gravity and corresponding wheel axle centre of gravity

$C_{s p} \quad$ An empirical constant

$N \quad$ Rate of amplitude reduction with frequency

a Half of wheel gauge

$\left[F_{r}(\omega)\right] 37 \times 1$ force matrix for displacement excitations at the $r^{\text {th }}$ wheel contact point $(r=1,2 \ldots 8)$ due to vertical and lateral track irregularities

$\left[D_{1}\right] \quad$ Dynamic stiffness matrix

$S_{r}(\Omega)_{8 \times 8}$ Matrix describing spectral density functions for the eight wheel inputs in terms of spatial frequency $\Omega$ (cycle/m)

$\left[S_{r}(\omega)\right]_{8 \times 8}$ Matrix describing spectral density functions for the eight wheel inputs in terms of circular frequency $\omega$ (radian/s) 


\section{Appendix}

The rail vehicle used for present analysis is ICF General Sleeper Coach of Indian Railways. The values of the rail-vehicle and track parameters for the purpose of simulation are obtained from Indian Railways Research Department, Research Designs and Standards Organisation, Lucknow (India) and given in Table 3.

Table 3. Values of rail vehicle and track parameters

\begin{tabular}{|l|l|l|l|l|l|l|l|l|}
\hline S.N. & Parameter & $\begin{array}{l}\text { Parameter } \\
\text { value }\end{array}$ & S.N. & Parameter & $\begin{array}{l}\text { Parameter } \\
\text { value }\end{array}$ & S.N. & Parameter & $\begin{array}{l}\text { Parameter } \\
\text { value }\end{array}$ \\
\hline 1 & $m_{C}$ & $37960 \mathrm{~kg}$ & 19 & $c_{C B}^{z}$ & $0.035 \mathrm{MN}-\mathrm{sec} / \mathrm{m}$ & 37 & $k_{W}^{y}$ & $250 \mathrm{MN} / \mathrm{m}$ \\
\hline 2 & $m_{B}$ & $400 \mathrm{~kg}$ & 20 & $c_{C B}^{y}$ & $0.0175 \mathrm{MN}-\mathrm{sec} / \mathrm{m}$ & 38 & $k_{S L}^{y}$ & $50 \mathrm{MN} / \mathrm{m}$ \\
\hline 3 & $m_{B F}$ & $2346 \mathrm{~kg}$ & 21 & $k_{B B F}^{z}$ & $0.42375 \mathrm{MN} / \mathrm{m}$ & 39 & $k_{S}^{y}$ & $30 \mathrm{MN} / \mathrm{m}$ \\
\hline 4 & $m_{W}$ & $1487 \mathrm{~kg}$ & 22 & $k_{B B F}^{y}$ & $0.2324 \mathrm{MN} / \mathrm{m}$ & 40 & $k_{S S}^{y}$ & $50 \mathrm{MN} / \mathrm{m}$ \\
\hline 5 & $I_{C}^{x}$ & $63950 \mathrm{~kg} \mathrm{~m}^{2}$ & 23 & $c_{B B F}^{z}$ & $0.0589 \mathrm{MN}-\mathrm{sec} / \mathrm{m}$ & 41 & $c_{W}^{y}$ & $4 \mathrm{MN}-\mathrm{sec} / \mathrm{m}$ \\
\hline 6 & $I_{C}^{y}$ & $1470750 \mathrm{~kg} \mathrm{~m}^{2}$ & 24 & $c_{B B F}^{y}$ & $1 \mathrm{MN}-\mathrm{sec} / \mathrm{m}$ & 42 & $c_{S L}^{y}$ & $10 \mathrm{kN}-\mathrm{sec} / \mathrm{m}$ \\
\hline 7 & $I_{C}^{z}$ & $1473430 \mathrm{~kg} \mathrm{~m}^{2}$ & 25 & $k_{B F W A}^{z}$ & $0.26935 \mathrm{MN} / \mathrm{m}$ & 43 & $c_{S}^{y}$ & $50 \mathrm{kN}-\mathrm{sec} / \mathrm{m}$ \\
\hline 8 & $I_{B}^{x}$ & $307 \mathrm{~kg} \mathrm{~m}$ & 26 & $k_{B F W A}^{y}$ & $11.5 \mathrm{MN} / \mathrm{m}$ & 44 & $c_{S S}^{y}$ & $70 \mathrm{kN}-\mathrm{sec} / \mathrm{m}$ \\
\hline 9 & $I_{B}^{y}$ & 00 & 27 & $c_{B F W A}^{z}$ & $0.0206 \mathrm{MN}-\mathrm{sec} / \mathrm{m}$ & 45 & $t_{C}$ & $0.8 \mathrm{~m}$ \\
\hline 10 & $I_{B}^{z}$ & $336.5 \mathrm{~kg} \mathrm{~m}^{2}$ & 28 & $c_{B F W A}^{y}$ & $0.5 \mathrm{MN}-\mathrm{sec} / \mathrm{m}$ & 46 & $t_{B}$ & $1.127 \mathrm{~m}$ \\
\hline 11 & $I_{B F}^{x}$ & $1546 \mathrm{~kg} \mathrm{~m}$ & 29 & $k_{W}^{z}$ & $1000 \mathrm{MN} / \mathrm{m}$ & 47 & $t_{W}$ & $1.079 \mathrm{~m}$ \\
\hline 12 & $I_{B F}^{y}$ & $2893 \mathrm{~kg} \mathrm{~m}$ & 30 & $k_{S L}^{z}$ & $65 \mathrm{MN} / \mathrm{m}$ & 48 & $l_{A}$ & $0.285 \mathrm{~m}$ \\
\hline 13 & $I_{B F}^{z}$ & $4298 \mathrm{~kg} \mathrm{~m}$ & 31 & $k_{S}^{z}$ & $20 \mathrm{MN} / \mathrm{m}$ & 49 & $z_{12}$ & $1.3275 \mathrm{~m}$ \\
\hline 14 & $I_{W}^{x}$ & $1181 \mathrm{~kg} \mathrm{~m}^{2}$ & 32 & $k_{S S}^{z}$ & $35 \mathrm{MN} / \mathrm{m}$ & 50 & $z_{24}$ & $0.1435 \mathrm{~m}$ \\
\hline 15 & $I_{W}^{y}$ & $108.5 \mathrm{~kg} \mathrm{~m}^{2}$ & 33 & $c_{W}^{z}$ & $0.5 \mathrm{MN}-\mathrm{sec} / \mathrm{m}$ & 51 & $z_{46}$ & $0.194 \mathrm{~m}$ \\
\hline 16 & $I_{W}^{z}$ & $1181 \mathrm{~kg} \mathrm{~m}^{2}$ & 34 & $c_{S L}^{z}$ & $30 \mathrm{kN}-\mathrm{sec} / \mathrm{m}$ & 52 & $x_{12}$ & $7.3915 \mathrm{~m}$ \\
\hline 17 & $k_{C B}^{z}$ & $35 \mathrm{MN} / \mathrm{m}^{2}$ & 35 & $c_{S}^{z}$ & $40 \mathrm{kN}-\mathrm{sec} / \mathrm{m}$ & 53 & $x_{46}$ & $1.448 \mathrm{~m}$ \\
\hline 18 & $k_{C B}^{y}$ & $17.5 \mathrm{MN} / \mathrm{m}^{y}$ & 36 & $c_{S S}^{z}$ & $50 \mathrm{kN}-\mathrm{sec} / \mathrm{m}$ & 54 & $a$ & $0.871 \mathrm{~m}$ \\
\hline
\end{tabular}

\section{References}

Alfi, S., Bruni, S., Gialleonardo, E., and Facchinetti, A., 2010, Active control of air spring secondary suspension for improving ride comfort in presence of random track irregularity, Journal of Mechanical Systems for Transportation and Logistics, Vol. 3, No. 1, pp. 143-153.

Goel, V. K., Thakur, M., Deep, K. and Awasthi, B.P., 2005, Mathematical model to represent the track geometry variation using PSD, Indian Railway Technical Bulletin, Vol. LXI, No. 312-313, pp.1-10.

ISO 2631, 1997. Mechanical vibration and shock evaluation of human exposure to whole body vibrations- Part 1: General requirements.

Kalker, J. J., 1979, Survey of wheel-rail contact theory, Vehicle System Dynamics, No. 8, pp. 317-358.

Lee, J., Kwon, S., Kim, M. and Yeo, I., 2009, A parametric study on the dynamics of urban transit maglev vehicle running on flexible guideway bridges, Journal of Sound and Vibration, Vol. 328, Issue 3, pp. 301-317.

Nathoo, N. S. and Healey, A. J., 1978, Coupled vertical-lateral dynamics of a pneumatic tired vehicle: part 1- A Mathematical model, Journal of Dynamic System Measurement and Control, Vol. 100, pp. 311-318.

Nathoo, N. S. and Healey, A. J., 1978, Coupled vertical-lateral dynamics of a pneumatic tired vehicle: part 2- Simulated verses Experimental data, Journal of Dynamic System Measurement and Control, Vol. 100, pp. 319-325. 
Biographical notes

Ramji, K., 2004, Coupled vertical-lateral dynamics of three-wheeled motor vehicles, Ph.D. Dissertation, Deptt of Mechanical and Industrial Engg., I.I.T. Roorkee.

Watari, A. and Iwamoto, S., 1974, Application of sensitivity analysis to vehicle dynamics, Vehicle System Dynamics, Vol. 3, pp.1-16.

Weidemann, C., 2010, State of the art railway vehicle design with multi-body simulation, Journal of Mechanical Systems for Transportation and Logistics, Vol. 3, No. 1, pp. 12-26.

Zhai, W. M., Cai, C. B. and Guo, S. Z., 1996, Coupling model of vertical and lateral vehicle/track interactions, Vehicle System Dynamics, Vol. 26, No.1, pp. 61-79.

Zhai, W. M., Wang, K. and Cai, C., 2009, Fundamentals of vehicle-track coupled dynamics, Vehicle System Dynamics, Vol. 47, No. 11, pp. 1349-1376.

\section{Acknowledgement}

The support provided by Centre of Transportation Systems, Indian Institute of Technology Roorkee is thankfully acknowledged. The authors would also like to thanks Department of Testing, Research Designs and Standards Organisation, Lucknow (India) for providing the necessary data of an ICF General Sleeper Coach of Indian Railways for present analysis.

\section{Biographical notes}

R.C. Sharma received M.Tech. from Institute of Technology, Banaras Hindu University, Varanasi in 1998 and Ph. D. degree from and Indian Institute of Technology Roorkee in 2010. He is working as a Professor, Mechanical Engineering Department, Maharishi Markendeshwar University, Mullana (Ambala). His first degree in Mechanical Engineering is from Institution of Engineers (India). His area of research is rail vehicle dynamics and mechanical vibrations.

Received February 2011

Accepted September 2011

Final acceptance in revised form September 2011 